\title{
Active Methodologies-Blended Learning: From the Complexity to the Sense of Learning Experiences by Means of Significant Learning in Digital Culture Time
}

\author{
Augusto Niche Teixeira1, Vera Lúcia Ramirez², Claus Dieter Stobäus ${ }^{3}$ \\ ${ }^{1}$ Coordenator of Education and Culture Areas of Centro Universitário La Salle-UNILASALLE, Canoas, RS, Brazil \\ ${ }^{2}$ Academic Pro-Rectory of Centro Universitário La Salle-UNILASALLE, Canoas, RS, Brazil \\ ${ }^{3}$ Postgraduate Program in Education and in Biomedical Gerontology, Pontifical Catholic University of Rio \\ Grande do Sul-PUCRS, Porto Alegre, Brazil \\ Email: stobaus@pucrs.br
}

Received 11 April 2016; accepted 17 June 2016; published 20 June 2016

Copyright (C) 2016 by authors and Scientific Research Publishing Inc.

This work is licensed under the Creative Commons Attribution International License (CC BY). http://creativecommons.org/licenses/by/4.0/

(c) (i) Open Access

\section{Abstract}

This case report is the sharing of teaching practices and theoretical and epistemological reflections that bring together educational and methodological experiments in the Degree in Pedagogy in the field of higher education, the Centro Universitário La Salle-UNILASALLE, Canoas-RS, Brazil. The reported pedagogical proposition is founded on records and epistemological principles of the theory of complexity of Edgar Morin-highlighting the recursive thinking and dialogical perspective. Co-created pedagogical practices by professors and students in 2015 , in graduate degrees in Education, in different subjects and distinct themed areas, are a clear intent to promote active methodologies, whose nature allows students and teachers to argue about the role of teaching and learning processes and the attribution of meaning to learning. Significant experiences were presented in this paper bordering on approaches based on logic of blended learning, under the influence of concepts related to digital culture contemplated from Marc Prensky's ideas. This logic is configured on a methodology aimed at non-disjunction between classroom learning. The areas of knowledge of Pedagogy, Design and Information Technology are directly interrelated in this project. At the dawn of the third millennium, the introduction of educational and pedagogical practices under the logic of new languages becomes a sine qua non for the attribution of meaning and meaning to learning, when the priori new brain structures and cognitions emerge from new experiences and digital stimuli. The construction of knowledge through the prism of active methods is enhanced by the production of learning materials structured from the new languages derived from Digital Culture. It notes that the pedagogical practice based on active methods is not dogmatic and even absolutist, considering the required reading of the classics, philosophical 
thinking, reflective look about the art and the investigative approach enrolled in all forms of science. Active pedagogical practice must ensure the usefulness of teaching and learning processes that, in complex ways, can expand the possibilities of diverse practices and consequent investigations. Thinking the educational and pedagogical complex in the XXI century is therefore one of the greatest challenges of contemporary times.

\section{Keywords}

\section{Active Methodologies, Creative Intelligence, Complexity, Hybrid Education}

\section{Introduction: Recognition Reductionist Perspectives-Understandings of Openness to Complexity}

In order to understand and act on the complexity of the phenomena that make up the search for sense and meaning through the teaching and learning processes, it is necessary to advance on the frontiers of knowledge, guarded by the disciplinary battalions that ensure mutilating thinking in academic-school educational sphere. This reductionist way of thinking remains in the academic and scientific rationality. Once past the third millennium dawn becomes important for the development of academic and scientific thinking forward break uncertainties. To advance the science, so the determination that inspires the strength compared to the suffering caused by the rupture with the dresser stagnation installed in academic and educational institutions is necessary. Think complexity, in this light, which recognizes imprisonment to nonlinearities and reductionism, is not a challenge easy and simple dimension. No, at least when reductionism is the prisoner himself who keeps the prison. His/her (un)consciousness can also be the source of his imprisonment.

It is known that little was reflected in public and private schools by the beginning of the XXI century. In this light some students were encouraged to create as authors of that history-the school institution. What emerges is not the result of a totalitarian and reductionist thinking, but perceptions of teaching and learning in higher education and, therefore, is founded from the teaching experience at this level of education. As an inquiry, concerning the experience is recalled that several times history was taught without reflecting the historicity. The sciences were taught, but in the absence of learning and knowledge about the "why", "how" and "what", contexts and connections with the reality that is constituted as a bridge to the meaning and significance of learning.

The school gap is also the rare existence of similarities and interconnections between the learned and the possible problems presented in the life process, and in the absence of relationship between curricula and the existence (the other), the void of meaning and no meeting of otherness. The didactic-methodological point of view the interventional approach on responsibility for others and otherness can be qualified and made possible through Active Methodologies - whose centrality is embraced by the dialogic relationship between teachers, students and knowledge and learning objects. It is therefore plausible intelligent and dedicated only to curriculum organization and ideal teachers' bottlenecks of the educational process, although they are recursive factors that can feed back progress and stagnation in higher education institutions.

The text points to another possible methodological dimension, whose theoretical and practical and epistemological record can contribute to decisive attribution of meaning and significance of knowledge and learning. It was initially proposed for this discussion that a reflection on epistemological filters must be articulated as philosophical principles for understanding the removal of the phenomenon of teaching and direction, as well as learning and meaning.

In the pursuit for a theoretical and epistemological understanding, compatible with methodological record in focus sought to interconnect three axioms coming from contemporary philosophy. The relationship between the three axiomatic pillars may favor the construction of a teaching practice towards pedagogical clarity, the search for meaning through the implementation of Active methodologies. It is emphasized that the proposal of a teaching methodology needs fundamentally to be rooted in an epistemological record and established from a theoretical matrix to allow the teacher to align the speech and didactic-methodological practice in the classroom and other scholar academic environments. At this point, it becomes cautious and delicate academic approach on the three axioms. Do not just advertise them. It is necessary to define the epistemological and/or theoretical differences between the concepts that will perform a recursive movement throughout the text. 


\section{From the Complex Thinking to the Complexity}

Morin (2008: 45) says that:

The question was posed to children in a school: "What is complexity?” Response from a student: "Complexity is a complexity that is complex." It is evident that she had touched the heart of the matter.

For the development of active methods in pedagogy course-Teaching, of UNILASALLE (site: www.unilasalle.edu.br) the Complexity Theory proposed by Morin \& Moigne (2007) was a source for the statement of philosophical emphasis, sociological, psychological, anthropological and pedagogical. The epistemological lenses that present themselves as filters are three of the seven principles of Complexity Theory (Morin, 2005a): 1) Detecting error and illusion; 2) Principles of pertinent knowledge; 3) Teaching the human condition; 4) Earth identity; 5) Confronting uncertainties; 6) Understanding each other; and 7) Ethics for the human genre.

Therefore, it is important to be understood that the scientific revolutions and quality of human thought jumps promoted also the development of humanity.

As Teixeira (2008), during the fifteenth and sixteenth centuries from the ideas of René Descartes and Isaac Newton emerged significant front breaks the logic of reason of the medieval time. The rupture front of the logic traveled in the Middle Ages postulated from dogmas of the Roman Catholic Church, especially in this period represented the ideas of St. Thomas Aquinas and St. Augustine, the man of the modern age based on the Cartesian and mechanistic mathematical perspective of physically Newtonian, established absolute and irrefutable truth based on pure reason. In this context, it is important to remember that, in the Middle Ages the boundaries were uncertain between philosophy and theology.

After the introduction of new logics in the Modern Age scientific thought was built on streamlining, which would cover, therefore the reading of the world. It was revealed as scientific legitimacy and methodological validity of the proposition of scientific laws and absolute truths. It can be argued, therefore, that modern man from the work the Discourse on Method, proposed by Descartes, founded scientific processes based on measurability, in the formulation of absolute truths, parameterized by axioms that were about to order, separability and the absolutely right.

Therefore, it produced the guiding source of thought of modern man and, interestingly still remains, as the model of science produced and developed until today, after the close of the third millennium dawn. In some schools and universities, the essence of modern thought still resides as a parameter of pedagogical practices and foundation of the teaching action. The academic-school rationality reproduced under the fragmentary separability, the scientific model engendering linear curricula and educational-methodological propositions disjoint disciplinary.

Therefore, it became possible to postulate irrefutable inferences about the phenomena under the paradigm of certainty, even in times of uncertainty and impermanence. The problem enrolled in this academic-school issue is that emerged in the scientific and educational processes the axiom of negation as a guide for the support of absolute truth in the name of pure reason. From this perspective, through the modern classical thought, the man sought the explanation of the world and the various phenomena, producing definitions often defined in only reasons that gave rise to laws that reduced reality, synthesizing it.

In school and academic sphere, the classical view of science was the educational action and to teaching, especially as regards the methods and learning processes about knowledge. It should be noted that for a long educational and school processes were understood a relationship between the expectation of internalization and the inculcation of knowledge/knowledge, according to the world of reading and their logic teacher and/or school (education) as a state apparatus. In academic and educational media for decades in the Twentieth Century teachers "transmitted" universal accumulation of knowledge to the students so that they could be characterized/be as "human encyclopedia”, full heads, not necessarily well-made as stated Morin (2005a, b, c, d, e). In this line, teachers of different educational levels, proposed the evaluation of "learning" and evaluating the production of students according to their expectations, often disregarding the hybrid and heterogeneous logic traveled by students in the same class in the process of learning.

It is announced thus the Complexity Theory as an epistemological field of reflection-action. Complex thinking leads us to reflect on the importance of reconnecting the fragments of knowledge and learning. As Morin (2008) proposes, the religion of knowledge. Think the complexity is a sine qua non and, at the same time, the biggest challenge of contemporaneity, because it is an invitation to transcend the barriers created by man in the 
direction of knowledge and science, body and soul, life and death, the human and the inhuman, and all other phenomena.

The complexity theory, proposed by Morin (2005b), has a high degree of importance to the qualitative leaps of an epistemological review, to study the history of humanity, as well as to reform the thinking and understanding of new paradigms of science.

\section{The Epistemological Lens of Complexity: Principles of Educational Reform}

A profound educational reform permeates theoretical and epistemological break. Thus, the object of active methodologies was understood from the principles of Complexity Theory. It is noteworthy in this study three of the seven principles-Dialogic, the Recursive and holographic. Under the approach, adopted dynamic movement established between these principles allows an approach that integrates and defines the more complete understanding considering the complexity of the phenomena attached to the teacher.

For Teixeira (2008) dialogic principle, according Morin (2008) idea, part of the living organization. The concept has been designed according to the relationship and the meeting of two logical from physical and chemical classifications. Since a part of the instability of a protein that is organized and lives in contact with the medium, allowing the existence and one that maintains and ensures reproduction. Order and disorder are processes that comprise this logic, since they are antagonistic, but not deny, and often produce the organization and formed complexity. The dialogic principle is related to the idea of unity but not uniformity.

For Morin, \& Moigne (2007), the dialogic principle considers and contemplates the possibility of dialogue and existence of a relationship in unity between order and disorder, two or more truths, the similar and antagonistic, homo sapiens and homo demens, life and death, characterizing the break against the absolutism present in reductionist classical thought. This is the duality at the heart of the unit.

From the perspective of dialog is founded the first educational-methodological filter, which was named in Teixeira (2008) as the "Sense Dialogic" and which is currently reframes as the "Dialogic Methodology", in which there is no horizontal and/or verticality, but a reading of the whole and does not address the reality from the principle of exclusion/absolutist denial.

Therefore, will not be built relationships in a closed pre-established model. Relations and interpretations will according to the emergencies, ongoing trials. In this sense, discourses, practices and investigative experiences pervade by a methodological filter where nothing is denied due to the linearity, but where the whole is a construction meant the relationship between perceptions of the researcher and the researched phenomenon.

The second methodological filter is postulated from the idea of recursion, which positions itself as the "Recursion of the teaching."

This filter assumes that reality is constituted so that the products and the effects are both the producers and the causes of producing them. That is, the learning instruction also determines that turn back onto the learning process. It is this movement that emerge from the methodological architecture and the pillars that underlie the teaching. In this case, the Lasallian University Education. This concept is interconnected also essentially the retroactive principle of Complexity Theory. Transcends, therefore, the perception of biology, also leaving for a possible sociological perspective.

According to Morin (2001:108):

[...] The company is produced by interactions between individuals, but society, once produced, back onto its individuals and produce them. If there were a society and its culture, a language, a knowledge acquired, we would not be human individuals. In other words, individuals produce society produces individuals. We are simultaneously produced and producers.

Recursion ascends the thought of facing break the linear determinism idea of cause and effect. Thus, it introduces the idea of self-organizing systems. The above filter plunges into the conceptual field that refers to the "how" and under "what" perspective the education phenomenon will be observed and analyzed by the teacher in a reflective-critical movement. The last methodological filter search lucidity from the holographic principle, proposed by Morin (2008). The name, in this light, is given as the "Learning hologramatic" filter. In this case, the concept of hologram points to the complexity factor.

Morin (2001), even the smallest point hologramatic may contain "almost all” of the object information. Pascal said he considered not conceive and know the whole without knowing the parts and the parts without design and know all. From the perspective of biology hologram idea can be expressed and/or translated in the formation of 
cells, because each cell is contained in the "totality" of the genetic information of the organism.

This perspective on the phenomenon puts a lens comprising individual/collective, subjective/intersubjective, part/whole time/space, man/woman, teacher/student, teacher/institution and beings/systems. Thus, learning is constituted of all the individual learner and assumptions of the subject teaching being, until the moment that the subjects concerned with dialogic form the condition of the other, creating openness to new skills and knowledge through meaningful learning experiences. The approach on the knowledge and expertise includes the whole, the parts, and the influences of all of the fragment and fragment on the whole, as well as wholes on the wholes and fragments of the fragments.

\section{Active Methodologies as Playful and Educational-Methodological Resource in Education Course}

This section presents the pedagogy course experience-Degree at UNILASALLE. The pedagogical approach through active methodologies make up the methodological repertoire of University Pedagogy of the La Salle University Center. The ability to move in the direction of teaching qualitative leaps was expanded from a methodological process that puts in constant dialogue students and teachers, protagonists of recursive processes of teaching and learning.

Language and Blended Learning. The language of blended learning is the key point of this pedagogical proposal. The blended learning term or B-learning refers to an educational methodological training system through which the knowledge and expertise, mostly, are built through a dialogic process between classroom and distance learning, as well as from the use informational, analog and digital technologies applied to education. Normally this proposal is given via the Internet, but includes necessarily face situations. Therefore, the origin of the blended denomination, which may mean something mixed, combined and/or mixed.

In the case in point, the proposals took place in person, including technological resources and the Internet for research and expansion of sources of information related to the proposed pedagogical challenges.

Thus, in two subjects corresponding to the Pedagogy Course curriculum-Officials Interdisciplinary and Multiple Languages-they have been implemented in some classes of the semester 2015/1, systematic, didactic-methodological proposals with the use of mobile devices connected to the Internet such as search engine and cocreation of solutions to be presented to the challenges presented. This strategy is justified not only by the constant data repository on the web/cloud, that can contribute to the formulation of ideas and theoretical and practical concepts and theoretical and epistemological. But especially by languages and arranged interfaces on websites, blogs and applications that match the aesthetic point of view and design to contemporary languages used in the main informational pathways globally.

This is a qualitative phenomenon analyzed from lenses and methodological procedures that refers to the type and qualitative nature. Thus, there was greater involvement of the class by assigning sense and meaning to learning, since the digital resources structure the playfulness of bridges as propellant factor of significant learning experiences. Thus, the student speech, representing $88 \%$ of the participant group showed improvements and qualitative leaps in the development process of both disciplines when resources were inserted that support education "mixed" (blended), whose objective was the methodological contribution to the process of assigning sense and meaning given by the learner, through meaningful learning experiences. Thus, in this context, there is no presentiality or distance but an education founded in hyper reality in Digital Culture time with digital and information resources in classroom teaching.

\section{Fundamental Remarks}

The action-reflection-action, fundamental movement for the construction of teacher identity and the teaching profession in the development of a University Education.

On Higher Education, which its role in the contemporary world in Digital Culture time? Do University professors reproduce archaic educational-methodological models in the classroom? Are students educated to the uncertainty and impermanence today? How does Education reflect the new cultures? Once enrolled in a Digital Culture Education, which is the academic-scientific and pedagogical models for the development of human thought and scientific rationality? What epistemology and theories emerge in this new scenario? What for and why do we teach? Rhetorical Questions to open the reflection-criticism and in the first instance, individual. 
So we think a reform of education, reforming our thinking about education as proposed in Morin (2008).

This means (re)learn about what is to be a teacher and consisting of teaching commitment, as Teixeira (2012: 1):

Think about the complexity of the phenomena that constitute the search of the human condition becomes necessary to transcend one mutilating and fragmentary thought that remains in the academic and scientific rationality. It is essential to be more open in the face of uncertainty. To overcome, advance and develop about life, it is necessary to determine that inspires strength compared to the suffering caused by the rupture with the dresser stagnation. Think complexity, still attached by some nonlinearities and reductionism is not an easy challenge proportion. The approach that this text is referred to as linear and reductionist, in many instances, emerging and/or sustained is also a result, even partially, school educational experiences, family and social mutilating, fragmented and without the emotion that brings meaning for living. However, it is not simply a deterministic and linear causality.

It is important to submit to the reader's consideration two fundamental questions. What makes people feel a desire to learn? What are the most precious and significant memories that remain of the period? In this sense, probably, people do not remember mathematical formulas, do not think of rules and grammatical formulations, even in the capitals of certain countries and/or specific knowledge that configure an egress profile graduations. Nevertheless, perhaps remains the group of people, and especially record the experiences that have made significant academic space and that, therefore, contributed to the attribution of meaning to build content. What contributes to the learning pass through for meaningful experiences? The University is "connected with your time?"

It is important to consider that nowadays the educational processes arising from academic spaces, constant and non-linear way, invaded by phenomena resulting from a Digital Culture.

For Prensky (2005), Digital Culture in the academic context it is characterized especially by the change of teachers' roles and students, as protagonists of the processes of teaching and learning, provided Instructors and learners, once transformed the human relationship with information and knowledge. From this idea the "teaching" presupposes science and discipline as a means for the construction of the meanings of knowledge, in different ways, complex and not absolute. It is stated, therefore, that the content taught should be related to the reality and what is experienced by the teacher and the learner, with teachers and students, the dialogic actors of both definitions.

To Prensky (2012b), the time we live in the educational sphere is characterized as a milestone because for the first time the students are no longer limited and/or restricted by/to the attention of his teachers. In this context, the University enrolled in a Digital Culture is undoubtedly time to scientific buildings and unscientific about reality beyond curricular teaching. Thus, to contemplate learning their teachers need to speak the "language" of their students. Is this happening?

As Prensky (2012a: 61):

One of the biggest questions with which Digital Immigrants (parents and teachers) face is: should we force our children to learn our Digital Natives old methods or should we, Digital Immigrants learn the new? The answer, I think, is obvious. No matter how the immigrants wish, the Digital Natives do not turn back. First, not work: their brains probably have different standards of our own.

It adds to the scenario, briefly announced, digital cultures, especially since the 90s have transformed the relationship between information, human, language and communication, permeated by a complexity of interrelated factors that lead to the urgent need rethink the processes of teaching and learning. The University of XXI century cannot teach to the twentieth century, based on outdated or obsolete technologies, and only on theoretical and epistemological logics derived from the XVI, XVII, XVIII and XIX.

In this sense, it is important to be attentive to what should permeate these learning experiences in academic and school context, to the point that are meaningful learning experiences. So we put as a fundamental source of these learning experiences-excitement. Emotion understood from the Chilean thinker's perspective Maturana, Magro, Graciano, \& Vaz (1997: 170):

Human existence takes place in language and rational starting from emotional and, [...] all human actions, regardless of the operating space in which they give, are based on emotional because they occur within specified actions by emotion. The reason too.

How to thrill, give sense and meaning to the learning process of digital natives, when the "language" is not the same and/or similar?

As Prensky (2012a: 58):

Today's students-from pre-school to college-are the first generation to grow as this new digital technology. 
They spent their entire lives surrounded by computers, video games, DVD players, video cameras, mobile phones, on-line auction sites, iPods and all other toys and tools of the digital age, using them all.

What are the actual processes of change implemented in higher education institutions in this direction? This is not only to acquire new technologies, but also to take on new languages, new sources, new horizons and paths to the educational process. Active methodologies can contribute as bridges to the attribution of meaning and meaning in/of teaching and learning processes.

To understand the meaning and significance of teaching and learning, it is necessary to recognize a university that for centuries hidden feelings and emotions in the pursuit of science for science, science without conscience. Other contemporary issues, interconnected, marking the school's hidden face are how to learn digital natives? How to teach them? About what will we teach them? What are the influences and how necessary are the technologies? At the end of the third millennium dawn, many of the children received at school pervade through different learning experiences in their homes and in other settings. Digital culture permeates various structured logic of academic learning contexts and non-academic, scientific and non-scientific.

Students research at home via www.google.com.br and www.youtube.com.br information regarding numerous curricular content, by different routes, and audio natures, video, animation and other forms of language. And when they reached the classroom, the same students, face against the dark abstract and unattainable and thus the Unreachable takes care of the educational and methodological processes. Teachers and students speak different languages in classes, in which contents are dumped on the minds.

A significant portion of the forms of languages used in contemporary society for the promotion of information and the construction of knowledge permeates the technological logic of interactivity and "user friendliness". So we could say that the teacher beyond the first commitment that is at the service of student learning, is responsible for lighting the "flame" inspiring front of knowledge, presenting the "friendliness" through mediated interactivity?

This text talks about an initial reflection on the need for a new pedagogy. However, it is critical thinking and rethinking pedagogies already formulated and corresponding epistemologies in order to find meaning for Education in the Twenty-first Century. It is in this sense that the complex thought becomes pillar for a reform of the educational and academic thought.

For Morin (2000b: 213):

Complex thinking is, therefore, essentially a thought that deals with uncertainty and is capable of conceiving organization. It is thought able to gather, contextualize, globalize, but at the same time to recognize the unique, individual, concrete [...] can not be reduced or science or philosophy, but allows their communication, like a vessel working to connect the wires.

In this sense, the paradigmatic perspective of a supposed digital culture that is understood by the university and its actors, can contribute to building more human and educational processes in an attempt to bring out human actions among humans in education and academic life.

According to Morin (2001: 41), "I believe it is necessary to say today: we are brothers because we are lost in a suburban planet, a suburban sun, a peripheral galaxy, a world devoid of center.”

We must remember the possibilities of the human spirit, the diversity of life, need each other to each other. There is talk at this time of teachers and students enrolled in the inseparability of the complex,

According to Teixeira (2008, p. 33):

Where there is the presence of certainty may be the pain of transformation and even the denial of new and different. Where prevail one reason may be suffering against one of the most complex phenomena that can not be summarized by the laws of man and the sciences, life. Mean and reframe our perceptions of the lived world is essential to stay alive, because when we come to the conclusion that we are ready, we are stagnating our thinking, our action, our life.

It is therefore that for Morin (2008:65):

EDUCATION should contribute to a person's self-training (teaching to take on the human condition, how to live) and teach how to become a citizen. A citizen is defined, in a democracy, for solidarity and responsibility towards their homeland.

The possible construction of experiences and experiences that result from human and technological relations between beings and systems is based at the heart of dialog and resilience. Thus emerges learning meaningful. The school life without meaning is the same as establishing relationships meaningless. It is also the same as learning what you do not understand and understand without understanding. 


\section{Conclusions}

The action-reflection-action movement is fundamental for the construction of teacher identity and the teaching profession in the development of a University Education.

In this sense it is necessary on the part of teachers and students systematic inquiries on Higher Education. What is your role in the contemporary world in Digital Culture time? University professors reproduce archaic educational-methodological models in the classroom? Today, students are educated to the uncertainty and impermanence? Education reflects the new cultures? Once enrolled in a Digital Culture Education, which is the academic-scientific and pedagogical models for the development of human thought and scientific rationality? What Epistemology and Theories emerge in this new scenario? For what and why teach? Rhetorical Questions open the reflection-criticism and in the first instance, individual.

So, we must think about a reform of Education, reforming our thinking about Education, as proposed in Morin (2008). This means (re)learn about what is to be a teacher and consistence in teaching commitment. To think about the complexity of the phenomena that constitute the contemporary education becomes necessary to transcend one mutilating and fragmentary thought that remains in the academic and scientific rationality. It is essential to be more open in the face of uncertainty. To overcome, advance and develop about life, it is necessary to determine that inspires strength, compared to the suffering caused by the rupture with the dresser stagnation.

It is important to submit to the reader's consideration two fundamental questions. What makes people feel a desire to learn? What are the most precious and significant memories that remain of the period? In this sense, probably, people do not remember mathematical formulas, do not think of rules and grammatical formulations, even in the capitals of certain countries and/or specific knowledge that configures an egress profile graduations. But perhaps remains the group of people, and especially record the experiences that have made significant academic space and that, therefore, contributed to the attribution of meaning to built content. What contributes to the learning do we have and give for meaningful experiences? The University is really "connected with your time?”

It is important to consider that nowadays the educational processes arising from academic spaces, constant and non-linear way, invaded by phenomena resulting from a Digital Culture. For Prensky (2010b) Digital Culture in the academic context it is characterized especially by the change of teachers' roles and students, as protagonists of the processes of teaching and learning, provided instructors and learners, once transformed the human relationship with information and knowledge. From this idea teaching presupposes science and discipline as a means for the construction of the meanings of knowledge, in different ways, complex and not absolute. It is stated, therefore, that the content taught should be related to the reality and what are experienced by the teacher and the learner, with teachers and students, the dialogic actors of both definitions.

To Prensky (2010a), the time we live in the educational sphere is characterized as a milestone because for the first time the students are no longer limited and/or restricted by/to the attention of his teachers. In this context, the University enrolled in a Digital Culture is undoubtedly time to scientific buildings and unscientific about reality beyond curricular teaching. Thus, to contemplate learning their teachers need to speak the "language of their students". Is this happening? As he says, digital natives do not turn back in the direction of old and archaic methods produced by digital immigrants. It would not work a priori, because their brains probably have different standards of our own.

It adds to the scenario, briefly announced, digital cultures, especially since the 90 s have transformed the relationship between information, human, language and communication, permeated by a complexity of interrelated factors that lead to the urgent need rethink the processes of teaching and learning. The University of XXI century can not teach to the twentieth century, based on outdated or obsolete technologies, and only on theoretical and epistemological logics derived from the XVI, XVII, XVIII and XIX.

In this sense, it is important to be attentive to what should permeate these learning experiences in academic and school context, to the point that are meaningful learning experiences. So we put as a fundamental source of these learning experiences-excitement.

Emotion is understood by Maturana, Magro, Graciano, \& Vaz (1997) perspective as the human existence is given and is in the language and rational starting from the emotional. The authors also states that all human actions are based initially on emotions, then transformed in rationality.

So, one might ask: how to touch, give sense and meaning to the learning process of digital natives, when the 
"language" is not the same and/or similar? What are the actual processes of change implemented in higher education institutions in this direction? This is not only to acquire new technologies, but to take on new languages, new sources, new horizons and paths to the educational process. Active methodologies can contribute as bridges to the attribution of meaning and meaning in/of teaching and learning processes.

To understand the meaning and significance of teaching and learning, it is necessary to recognize a university that for centuries hidden feelings and emotions in the pursuit of science for science, science without conscience. Other contemporary issues, interconnected, marking the school's hidden face are how to learn digital natives? How to teach them? About that teach? What are the influences and how necessary are the technologies? At the end of the third millennium dawn, many of the children received at school pervade through different learning experiences in their homes and in other settings. And digital culture permeates various structured logic of academic learning contexts and non-academic, scientific and non-scientific. Students research at home via google.com.br ${ }^{\circledR}$ and youtube.com.br ${ }^{\circledR}$ or www.google.com.br and www.youtube.com.br information or google and youtube, regarding numerous curricular content, by different routes, and audio natures, video, animation and other forms of language. And when they reached the classroom, the same students, face against the dark abstract and unattainable and thus the Unreachable takes care of the educational and methodological processes. Teachers and students speak different languages in classes, in which contents are dumped on the minds.

A significant portion of the forms of languages used in contemporary society for the promotion of information and the construction of knowledge permeates the technological logic of interactivity and "user friendliness". So we could say that the teacher beyond the first commitment that is at the service of student learning, is responsible for lighting the "flame" inspiring front of knowledge, presenting the "friendliness" through mediated interactivity?

This text-to-speech on an initial reflection on the need for a new pedagogy. However, it is critical thinking and rethinking pedagogies already formulated and corresponding epistemologies in order to find meaning for Education in the Twenty-first Century. It is in this sense that the complex thought becomes pillar for a reform of the educational and academic thought. For Morin (2008), complex thinking is essentially a thought that deals with uncertainty, understanding it, thus becoming able to conceive the organization. It is the type of thinking able to contextualize and globalize and also recognize the uniqueness and individual. Complex thinking does not bounds and is not limited to science, does not close in philosophy, but allows its communication, the overflow toward the systemic and complex.

In this sense, the paradigmatic perspective of a supposed digital culture that is understood by the university and its actors, can contribute to building more human and educational processes in an attempt to bring out human actions among humans in education and academic life. We must remember the possibilities of the human spirit, the diversity of life, need each other to each other. There is talk at this time of teachers and students enrolled in the inseparability of the complex, entered in a digital culture that does not separate them, but it gives different and new roles.

The possible construction of experiences and experiences that result from human and technological relations between beings and systems, is based at the heart of dialog and resilience. Thus emerges learning meaningful. The school life without meaning is the same as establishing relationships meaningless. It is also the same as learning what you do not understand and understand without understanding. It is therefore that for Morin (2008), Education should contribute to the self-formation of the person, teaching her to assume the human condition and teaching it to life, to the complexity. And then it will be given to Education for citizenship. For him, a citizen is defined by its solidarity and responsibility.

Education for life takes on an existential commitment, sense and meaning, and this idea leads us to the need for continuing education of teachers and students to socialize and develop in Digital Culture times.

Think complexity in a complex world is an interesting idea to understand the constant and recursive transformations between human and knowledge in Digital Culture times.

It is noted that there is the announcement of a new paradigm, and it presents changes and transformationswhich constitute the uncertainty and impermanence-and that necessitates a non-linear approach on the understanding of the university educational action. For learners of the twenty-first century, and core values founded on the ethics of understanding, one should consider the entertainment, the design (visual/aesthetic), science and its discoveries, spiritual, knowledge and pre-knowledge, the classic and the scholar, the modern and the postmodern, the analog and the digital. 


\section{References}

Maturana, H., Magro, C., Graciano, M., \& Vaz, N. (org.). (1997). A ontologia da realidade. Belo Horizonte: UFMG. [The Ontology of Reality]

Morin, E. (2001). O método 4: As ideias. Porto Alegre: Sulina. [Method 4: Ideas]

Morin, E. (2005a). O método 1: A natureza da natureza (2nd ed.). Porto Alegre: Sulina. [Method 1: The Nature of Nature]

Morin, E. (2005b). O método 2: A vida da vida (3rd ed.). Porto Alegre: Sulina. [Method 2: Life Life]

Morin, E. (2005c). O método 3: Conhecimento do Conhecimento (3rd ed.). Porto Alegre: Sulina. [Method 3: Knowledge of Knowledge]

Morin, E. (2005d). O método 5: A humanidade da humanidade (3rd ed.). Porto Alegre: Sulina. [Method 5: Humanity of Mankind]

Morin, E. (2005e). O método 6: Ética. Porto Alegre: Sulina. [Method 6: Ethics]

Morin, E. (2008). A cabeça bem-feita: Repensar a reforma, reformar o pensamento (14th ed.). Rio de Janeiro: Bertrand Brasil, 2008. [The Well-Made Head Rethink the Reform, Reform the Thought]

Morin, E., \& Moigne, J.-L. Le. (2007). Inteligência da Complexidade: Epistemologia e Pragmática. Lisboa, Instituto Piaget. [Intelligence Complexity: Epistemology and Pragmatics]

Prensky, M. (2005). In Educational Games, Complexity Matters Mini-Games are Trivial—But “Complex” Games Are Not an Important Way for Teachers, Parents and Others to Look at Educational Computer and Video Games. Educational Technology, 45, 22-28.

Prensky, M. (2010a). “Não me atrapalhe, mãe eu estou aprendendo”: Como os videogames estão preparando nossos filhos para o sucesso no século XXI-e como você pode ajudar! São Paulo: Phorte. ["Do not Mess with Me, Mother I'm Learning”: How Video Games Are Preparing Our Children for Success in the Twenty-First Century-And How You Can Help!]

Prensky, M. (2010b). O papel da tecnologia no ensino e na sala de aula. Conjectura: Filosofia e Educação, Caxias do Sul. [The Role of Technology in Teaching and Classroom]

Prensky, M. (2012a). Brain Gain: Technology and the Quest for Digital. New York: Palgrave MacMillan.

Prensky, M. (2012b). From Digital Natives to Digital Wisdom Hopeful essays for 21st Century Learning. Thousand Oaks: Corwin. http://dx.doi.org/10.4135/9781483387765

Teixeira, A. N. (2008). O reconhecimento da complexidade a partir da intervenção docente frente ao erro e ao erro construtivo: fonte de busca da humana condição. Dissertação (Mestrado em Educação)—faculdade de Educação da PUCRS, Porto Alegre. [The Recognition of the Complexity from the Front Teaching Intervention to Error and Constructive Error: Search Source of the Human Condition]

Teixeira, A. N. T. (2012). Tríade Recursiva da Complexidade. 9 ANPED Sul, Anais..., Universidade de Caxias do Sul, Caxias do Sul-RS. [Triad Recursive Complexity] 